\title{
Intensity enhancement of heat exchange in shell- tube heat exchangers with smooth pipes
}

\author{
Leonid Kushchev \\ Department of Heating and Ventilation \\ BSTU named after V.G. Shukhov \\ Belgorod, Russia \\ Nick_973gt@mail.ru \\ Evgeniy Yakovlev \\ Department of Roads and Railways \\ BSTU named after V.G. Shukhov \\ Belgorod, Russia \\ agd@intbel.ru
}

\author{
Nikolai Nikulin \\ Department of Heating and Ventilation \\ BSTU named after V.G. Shukhov \\ Belgorod, Russia \\ Nick_973gt@mail.ru \\ Alexey Feoktistov \\ Department of Heating and Ventilation \\ BSTU named after V.G. Shukhov \\ Belgorod, Russia \\ alexwolf79@mail.ru
}

\author{
Alla Alifanova \\ Department of Heating and Ventilation \\ BSTU named after V.G. Shoukhov \\ Belgorod, Russia \\ tgv@intbel.ru
}

\begin{abstract}
The climatic pecularities of the Russian Federation territory that determine the duration of the heating season are considered. The number of operating heating sources of large, medium and low power is reflected. The equipment wear rate of the heating sources is defined. The emphasis is placed on the need to use shelland-tube heat exchangers in heating supply systems. The methods to intensify the heating exchange processes in such systems are studied. The research on fluid turbulence changes in a heating circuit of the heat exchangers is introduced, taking into account the different geometry of heat exchangers surface and speed modes. The authors considered the heat transfer surface elements and their location subject to the system construction introduced in Code of Regulations 41-101-95 «Design of heating units»
\end{abstract}

Key words-shell and tube heat exchanger, agitation, heat exchange, heat exchange coefficient

The significant part of the Russian Federation territory is located in extremely continental and moderately continental climate zones. Therefore, the heating season can last from 72 till 365 days per year. In order to create the favorable conditions for life and leisure, the heat supply systems are used. They produce the thermal power for heating, ventilation and hot water supply [1].

Thus, in 2015 according to the report of RF Ministry of Energy, 4.996. $10^{8} \mathrm{Gcal}$ of thermal energy was produced [2]. Currently, in RF, there are the following thermal energy sources [3]:
- nuclear power stations (NPS) - 10;

- thermal electric plants (TEP) - 485;

- heat-only boiler stations with thermal power up to 20 $\mathrm{Gcal} / \mathrm{h}$ - about 6 500;

- small-sized heat-only boiler stations - more than 100000

- autonomous individual heat generator - more than 600000 .

Herewith, a number of heat-only boiler stations with full wear-out reach about $60 \%$. With TEP, $25 \%$ of power boilers and $36 \%$ of turbines are under the operation less than 30 years (within the lifetime). To provide the further reliability of the thermal energy sources, a series of works targeted at reconstructions and technical replacement in basic and supplementary systems must be done.

According to the Sanitary and Building Standards in place and Thermal Equipment Operation Handbooks, there is the necessity to reduce the parameters of a heat carrying agent at the beginning. This reduction is required for pressure and temperature parameters. [4]. These requirements for irregularities indispensably will lead to some incidents throughout the period of lowest outdoor temperatures.

Heat exchangers are the main type of the thermal equipment to heat up a fluid in heat supply systems. This is especially relevant for housing and utilities infrastructure where the plate, shell and tube heat exchangers are used. 
The shell and tube heat exchangers are likely to be widely spread and have some operational advantages $[5,6,7]$ :

- possibility to be used as a heat carrying agent in liquids and in high pressure steam;

- possibility to be used simultaneously in two different aggregative states of heat carriers - steam in a heating part and water in a heated part and vice versa;

- long operation time in case of the partial or full blinding of one or several pipes (not necessarily to auger heat exchangers until the heating season ends).

Such exchangers are widely used in steam and water boilers, at individual heat supply stations (IHSS) and at central heat supply stations (CHSS) for TEP and NPS.

Along with clear benefits, the shell and tube heat exchangers with smooth pipes, which are used in heat supply systems, have one significant lack - a relatively low coefficient of heat transmission. The value of it is not higher than $2500 \mathrm{~W} /\left(\mathrm{m}^{2} \mathrm{~K}\right)$.

Consequently, the implementation of shell and tube heat exchangers forces producers to manufacture such heat exchangers with large overall dimensions [8], particularly for big TEPs and NPSs. This leads in its turn to budget intensification.

Taking into account a common practice of using shell and tune heat exchangers, there is the need of intensification of heating processes in them. This is able to bring about the increase of the heat transfer coefficient and the decrease of overall dimensions.

Nowadays active studies are conducted with the aim to intensify heat transferring in case the liquid flows over a solid surface. The theoretical knowledge of this process was generated in the studies of S. Kutateladzah, A. Zhukauskasa, A. Hintse [9, 10, 11]. At present, these issues have been researched in papers of D. Alhasova, V. Kireev, A Anisin [12, $13,14]$. However, the main issue that must be solved is the increase of the heat transmission intensification due to the flow turbulence of heated liquid. In this case, there is a reduction of the laminar-flow film resulting in increasing the quantity of heat transmitted through the laminar-flow film.

It is important to note that the liquid speed in the laminar-flow film is virtually 0 and the thermal energy transmission from a wall to liquid is conducted with the heat conductivity. The thicker the laminar-flow film, the less the heat transmitted through it. Consequently, decreasing the laminar-flow film thickness of the liquid contributes to increasing the heat transmission (increase of the heat transfer coefficient) through this layer. Different technical approaches are applied for achieving this goal, mostly connected with the changes in the heat exchanger surface geometry:

- installation of plates in exchangers and in sheet profile pipes [15];

- screens used to distribute heat agent flows; electrostatics field use [16];

-smooth pipes elbowed in the form of a helix [17];

- heat transmission pipes with grooves, circular cambers on the external and internal surface [18];
- longitudinal ribs outside and inside of the heat exchanging pipe [19];

-different cambers (ribs) of different geometry on the flat surface [20], etc.

The authors find it expedient to use the smooth pipes with changed geometry, equipped with plates having cylindrical form ribs that allows increasing the heat transfer coefficient in shell and tube exchanger, due to the increase of the liquid flow turbulence [20].

Let us consider the mechanism of heat processes intensification used in heat exchangers when the liquid flows over a solid surface.

It is known that the main characteristics of heat exchangers is heat transmission coefficient $\mathrm{k}$, which is calculated with the formula [8]:

$$
\mathrm{k}=\frac{\Psi \cdot \beta}{\frac{1}{\alpha_{1}}+\frac{\delta_{\mathrm{st}}}{\lambda_{\mathrm{st}}}+\frac{1}{\alpha_{2}}}
$$

where $\Psi$ - heat exchange efficacy coefficient (for a smoothpiped water heater backed with shelves, for a smooth-piped water heater backed with the walls blocks, for sheet profile pipes backed with the walls blocks);

$\beta$ - coefficient, including pipe surface pollution depending on the chemical properties of water, $\alpha_{1}$ - heat transfer coefficient (form liquid), flowing in the tubular space to the inner pipe surface, $\alpha_{2}$ - heat transfer coefficient from the outside pipe wall to the heated liquid flowing in the intertubular space.

According to the formula, the basic thermal-physical and hydrodynamic values influencing the heat transfer coefficient are coefficients $\alpha_{1}$ and $\alpha_{2}$. That is to say, in order to increase $\mathrm{k}$, one must increase $\alpha_{1}$ and $\alpha_{2}$. Obviously, the heat transfer coefficient is in direct proportional dependence on $\alpha_{1}$ and $\alpha_{2}$

Heat transfer coefficient $\alpha, \mathrm{W} /\left(\mathrm{m}^{2} \cdot{ }^{\circ} \mathrm{C}\right)$, from the heated heat exchange surface is calculated as:

$$
\alpha=\frac{\lambda N u}{l}
$$

where $\lambda$ - thermal conductivity coefficient (of the body), depending on the temperature, $\mathrm{W} /(\mathrm{m} \cdot \mathrm{K}) ; \mathrm{Nu}-\mathrm{Nu}$ number; $l-$ diagnostic geometrical surface parameter (for the plate - the length (m); for the cross-cut flowed pipe - its diameter (m).

$\mathrm{Nu}$ number is the most important and complex value, which is calculated with the empirical formula, found in the course of some experimental studies. All this depend on the liquid fluidity mode (laminated or turbulent). For the turbulent mode, $N u$ number is calculated as [21]:

$$
N u_{l}=0,037 \cdot \operatorname{Re}_{l}^{0,8} \cdot \operatorname{Pr}_{l}^{0,43}\left(\operatorname{Pr}_{l} / \operatorname{Pr}_{c n}\right)^{0,25}
$$

where $R e_{l}$ - Reynolds number which increases with liquid flow turbulence, $\mathrm{Pr}$ - Prandtl number.

Formula (3) shows that when numbers $\operatorname{Re}_{l}$ and $P r$ increase, number $N u_{l}$, also increases, but formula (2) indicates that 
when $\mathrm{Nu}$ grows up, heat transfer coefficient $\alpha$ also grows up.

Thus, according to calculations of A. Zhukauskasa [10], in Reynolds numbers (for flat surfaces) $2 \cdot 10^{3}-10^{4}$ with turbulence of heated liquid flow $\mathrm{Tu}=10 \%$, the heat transfer increase is $20-25 \%$.

Therefore, to intensify the heat exchange in the shell and tube heat exchanger, the liquid flow turbulence is needed, which flows over the heat exchange surface.

One way of increasing the liquid flow turbulence is placing some kind of an obstacle in the flow that means the change in the geometry of the heat exchange surface. In studies [10, 22], the authors considered a flow of an obstacle - single shank (fig. 1), placed on the flat plate. In so doing, behind the obstacle, the whirling turbulence of the flow is developed. At the distance of $8-12 \mathrm{H}$ of this zone ( $\mathrm{H}-$ the obstacle height), the turbulence of the flow has its maximum value. The maximum value at this distance will be either the heat transfer coefficient of the plate surface.

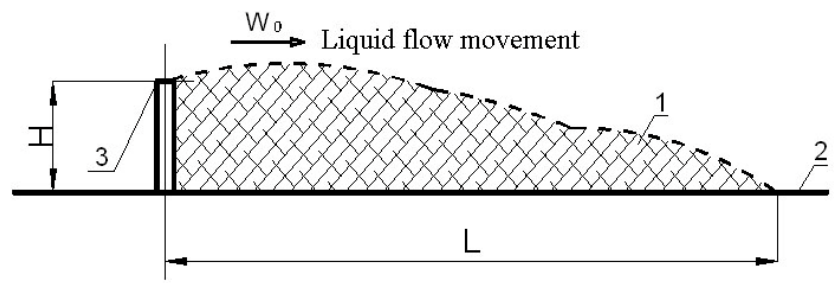

Fig. 1. Liquid flow movement behind obstacle. 1 - whirling flow movement, 2 - plate, 3 - obstacle height $\mathrm{H}$ (single shank), $\mathrm{W}_{0}$ - basic flow speed

Therefore, intensification of the heat exchange seems to be reasonable for using some kind of an obstacle on the flat surface for the heated liquid flow. Therewith the obstacle must be an element of the heat exchange surface.

Taking into account the liquid movement behind the obstacle, let us propose a scheme of the heat exchange surface consisting of a plate and a round semicylinder (fig. 2) [18].

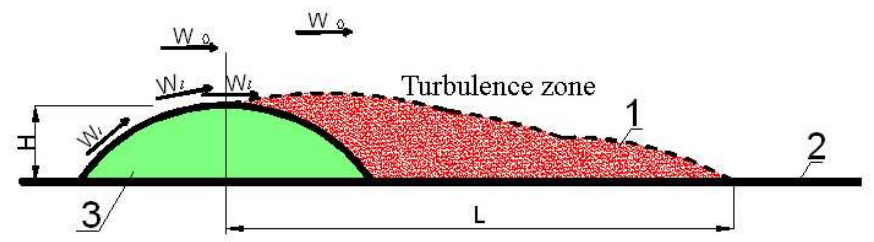

Fig. 2. Cylinder-formed rib of heat exchange surface: 1- cylinder (cross cut end), 2 - plate, 3 - cylinder-formed rib

In line with the research of $\mathrm{S}$. Kutateladzah and $\mathrm{G}$. Schlichting [9, 23], behind the cylinder, flowed over with the liquid flow, beginning with $\operatorname{Re}=60$, behind a stern, the intensive whirling flow is developed. When $\mathrm{Re}=5000$ and higher, behind the stern - full turbulence mess, vortex breakdown occurs at $\varphi=82^{\circ}(\varphi$ - angle from all parts of the cylinder). This leads to a decrease in the thickness of the laminar liquid sublayer on a plate and to a decrease of the thermal resistance of the laminar layer. This finally results in the increase of the heat energy transmission through this layer.
As the peculiarity of the shell and tube exchanger, let us propose that heat exchange pipes are equipped with the plates, which in their turn have the cylinder-formed ribs (fig. 3) [20]. Two ribs on the plate allow one to expand the thermal exchange surface and to create additional turbulence of the heated liquid flow when the liquid flows over the ribs.

It is important to note that the distance between ribs 1 and their height $\mathrm{H}$ is new constructive parameters for a heat exchanger, needed to determine the speed modes and exploitation [8].
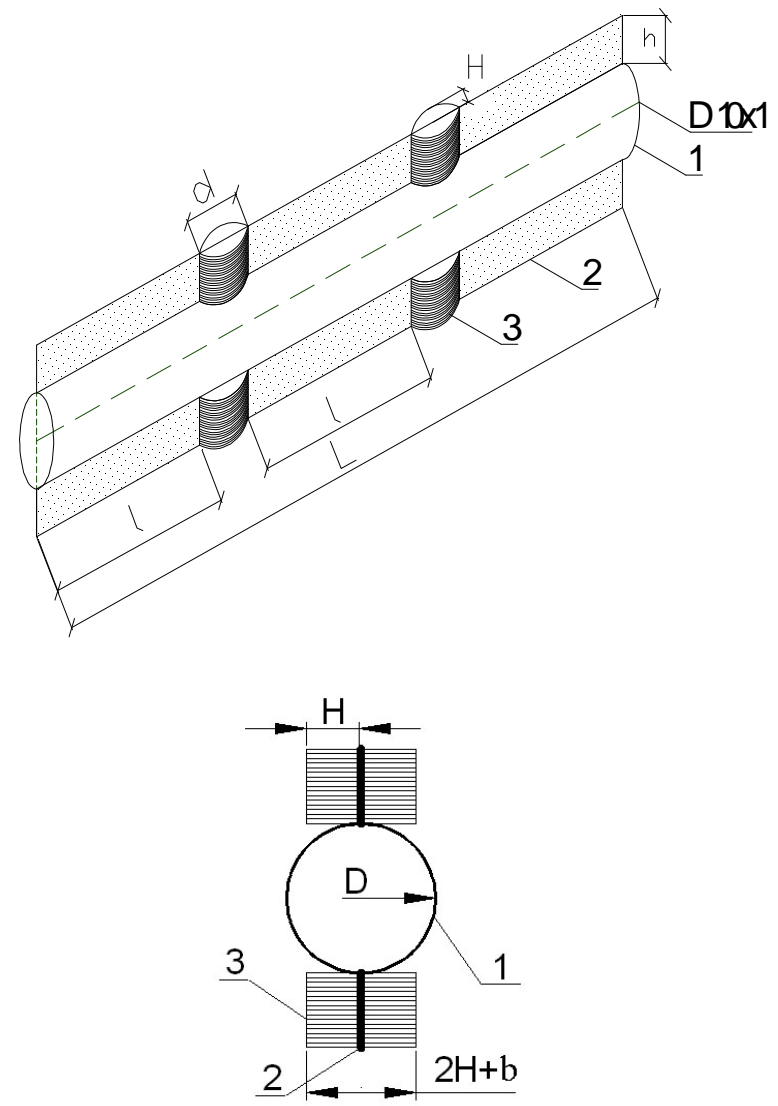

Fig. 3. Element of heat exchange surface in shell and tube exchanger. $1-$ pipe, 2 - plate, 3 - cylinder-formed ribs

The study on the turbulence, occurring on the heat exchange surface with changed geometry, was conducted with the software «Ansys CFX». This software is intended to develop math models in hydrodynamics, to solve a wide range of tasks and to examine in details the processes linked with gas and liquid flowing in different conditions (flowing over curved and flat surfaces with liquid, liquid leaking from the pipeline) [24].

At the beginning stage, when the optimal geometrical parameters of the shell and tube exchanger were determined, the searching experiment was carried out [25] with the geometrical parameters: $\mathrm{d}=8 \mathrm{~mm}, \mathrm{H}=4 \mathrm{~mm}$.

Then, the basic experiments addressed how influence changes the rib height and the flow speed in the zone with increased turbulence of the heated liquid. The experiments were conducted for the cylinder-formed rib with height 2, 4, 6 
$\mathrm{mm}$, and with the distance between centers of $70 \mathrm{~mm}$. The liquid speed for each value was $0.7 ; 1 ; 1.3 \mathrm{~m} / \mathrm{sec}$ [26].

The experiment's results are introduced in graphical allocation of the turbulence intensity with different speed of crosscut flow around the ribs of circular cross-section (fig. 3 5) with different heights.

After measuring the length of the turbulence zone, the following results in reference with length $l_{0}$ of the turbulence zone were achieved (fig. 1). The values were calculated as:

$$
l_{0}=\frac{l_{T U}}{H}
$$

where $l_{T U}$ - the whirling zone length.

TABLE 1. GEOMETRICAL PARAMETERS FOR ZONE WITH EXPANDED TURBULENCE

\begin{tabular}{|c|r|r|r|r|r|c|}
\hline $\begin{array}{c}\text { Height for } \\
\text { circular } \\
\text { cross- } \\
\text { section } \\
\text { rib, mm }\end{array}$ & \multicolumn{3}{|c|}{$\begin{array}{c}\text { Relative length of } \\
\text { turbulence zone with flow } \\
\text { speed, m/sec }\end{array}$} & \multicolumn{2}{|c|}{$\begin{array}{c}\text { Height of turbulence zone } \\
\text { over plate with flow } \\
\text { speed, m/sec }\end{array}$} \\
\cline { 2 - 7 } & $\mathbf{0 . 7}$ & $\boldsymbol{1}$ & $\mathbf{1 . 3}$ & $\mathbf{0 . 7}$ & $\boldsymbol{1}$ & $\mathbf{1 , 3}$ \\
\hline 2 & 8.75 & 10.94 & 11.65 & 3.51 & 3.52 & 3,58 \\
\hline 4 & 8.85 & 11.56 & 13.80 & 6.82 & 7.29 & 7,77 \\
\hline 6 & 9.43 & 9.76 & 10.29 & 12.1 & \multicolumn{3}{|c|}{ more $15 \mathrm{~mm}$} \\
\hline
\end{tabular}

In the course of the calculation-based experiment, the following results were obtained:

1. The relative length of the zone with expanded turbulence for the ribs with the height of 2, 4 and $6 \mathrm{~mm}$ and with the flow speed of $0.7 ; 1$ and $1.3 \mathrm{~m} / \mathrm{sec}$ lie within the range of $12 \mathrm{H}$, as shown in [10].

2. The height of the zone with expanded turbulence for the rib with the $2 \mathrm{~mm}$ height within speed values of 0.7 ; 1 and $1.3 \mathrm{~m} / \mathrm{sec}$ changes in a minor way (extension with each speed acceleration by $0.3 \mathrm{~m} / \mathrm{sec}$ does not exceed $1.7 \%$ ).

3. The height of the zone with expanded turbulence for the ribs with the height of $4 \mathrm{~mm}$ within speed values of $0.7 ; 1$ and $1.3 \mathrm{~m} / \mathrm{sec}$ changes averagely by $7 \%$.

The graphical view of allocations, the flow turbulence values are $10 \%$, and this corresponds a high turbulence degree according to A. Zhukauskas [10]. In the flow zones, where the turbulence is less than $10 \%$, the additional rib placing is possible. Thus, the optimal distance between the ribs can be identified due to which the zone of the expanded turbulence is held throughout the whole length of the heat exchange pipe that finally provides a high heat transfer coefficient $(\mathrm{k})$.

The experiment results let us draw to the conclusion that the increase in heat exchange (in the shell and tube heat exchanger with modified geometry) will be achieved if the height of a rib is $4 \mathrm{~mm}$, the speed is $0.7-1.3 \mathrm{~m} / \mathrm{sec}$, the length of whirling zone is $12 \mathrm{H}$.

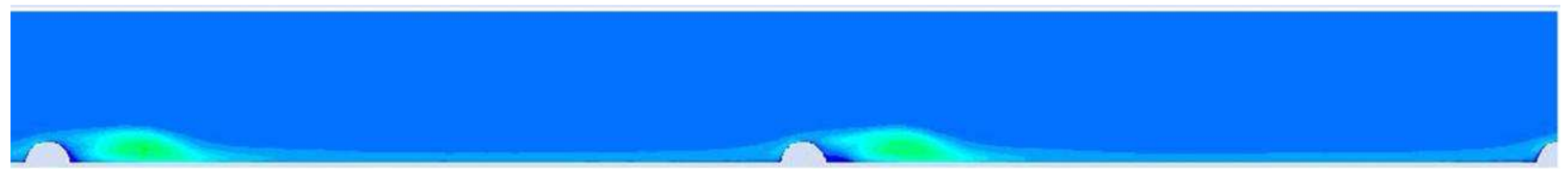

a) speed of crosscut flow is $0.7 \mathrm{~m} / \mathrm{sec}$

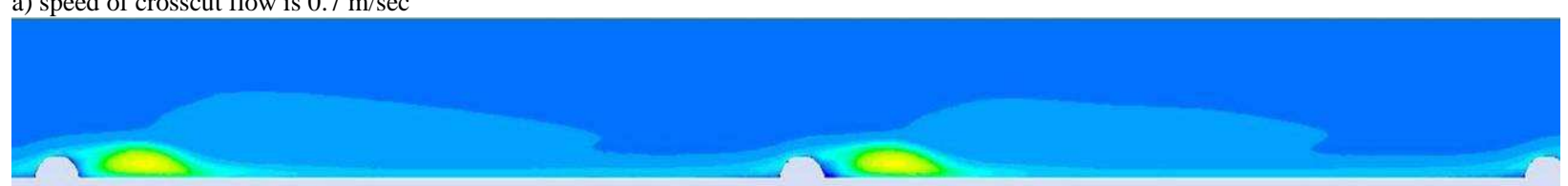

b) speed of crosscut flow is $1 \mathrm{~m} / \mathrm{sec}$

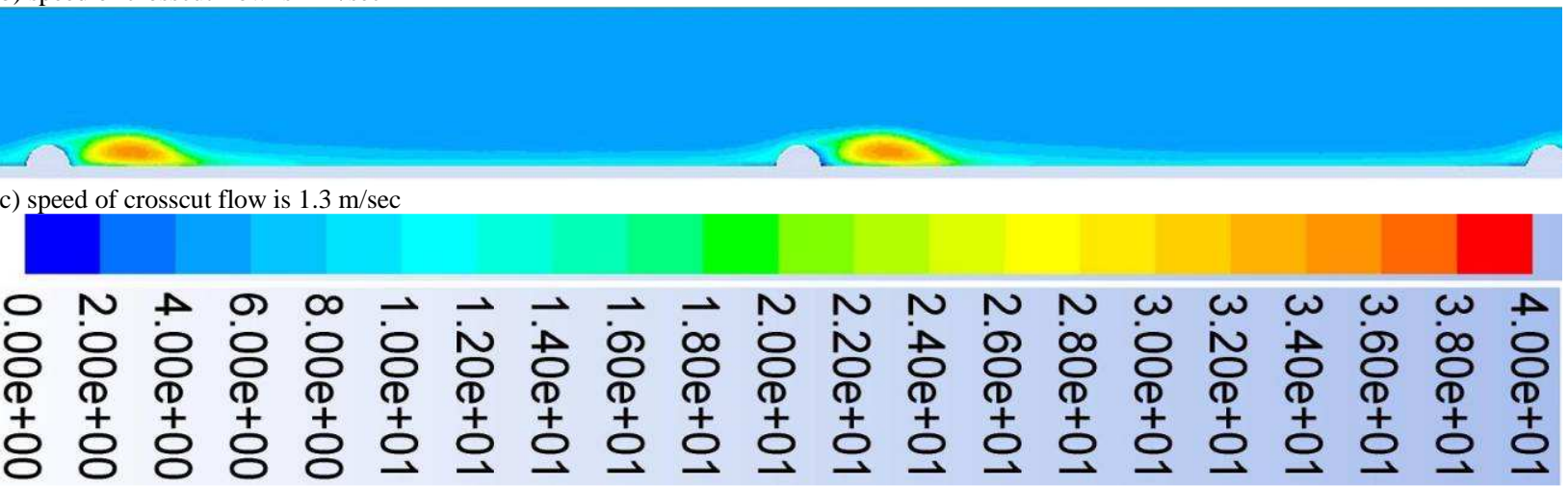

Fig. 4. Graphical allocation of the flow turbulence with different crosscut flow speed for cylinder-formed ribs, with $2 \mathrm{~mm}$ height.

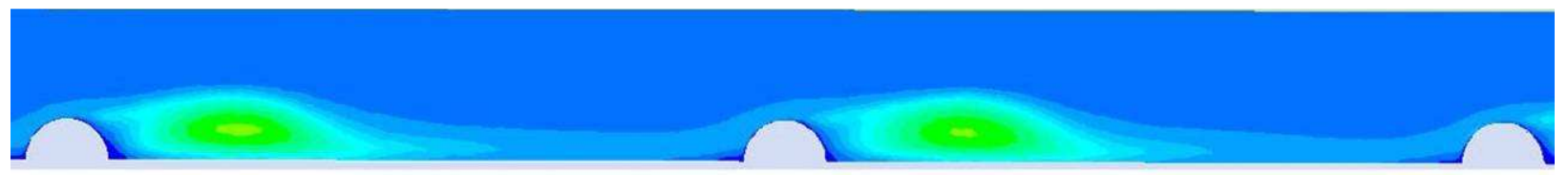




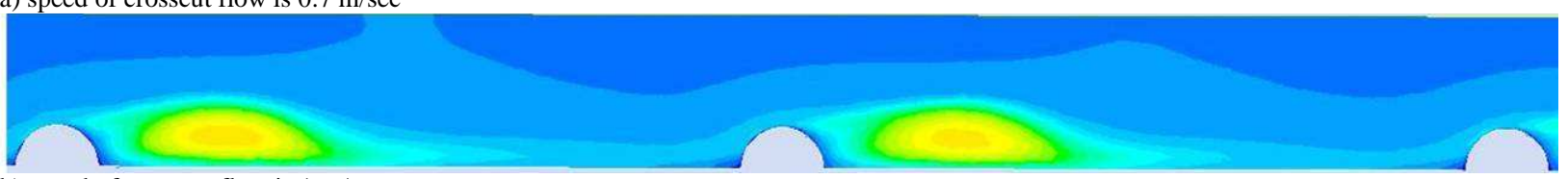

b) speed of crosscut flow is $1 \mathrm{~m} / \mathrm{sec}$

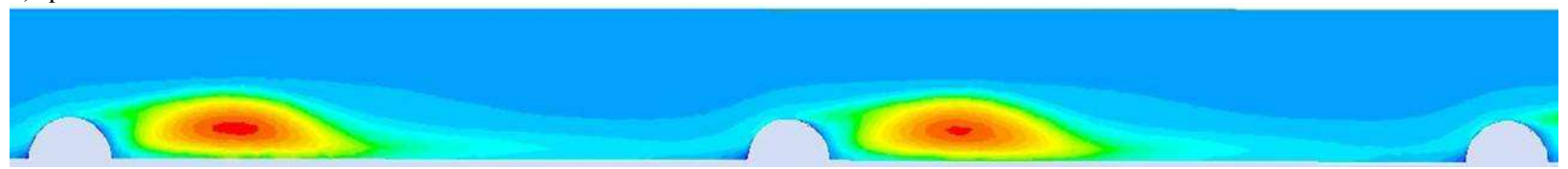

c) speed of crosscut flow is $1.3 \mathrm{~m} / \mathrm{sec}$

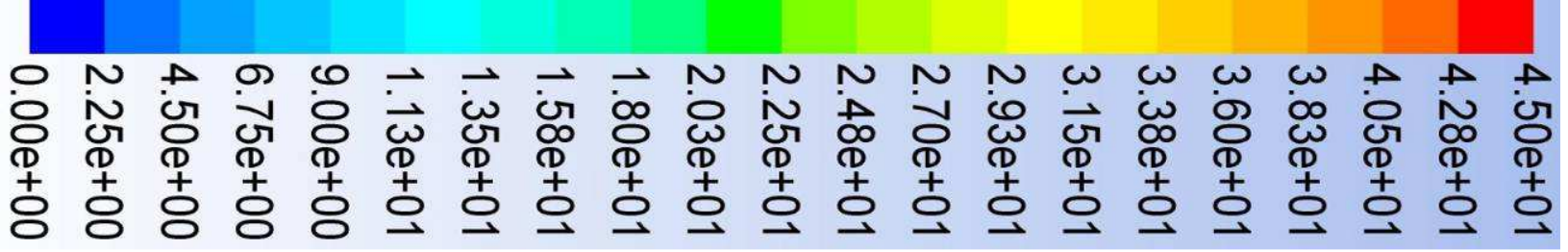

Fig. 5. Graphical allocation of the flow turbulence with different crosscut flow speeds for cylinder-formed ribs, with $4 \mathrm{~mm}$ height.
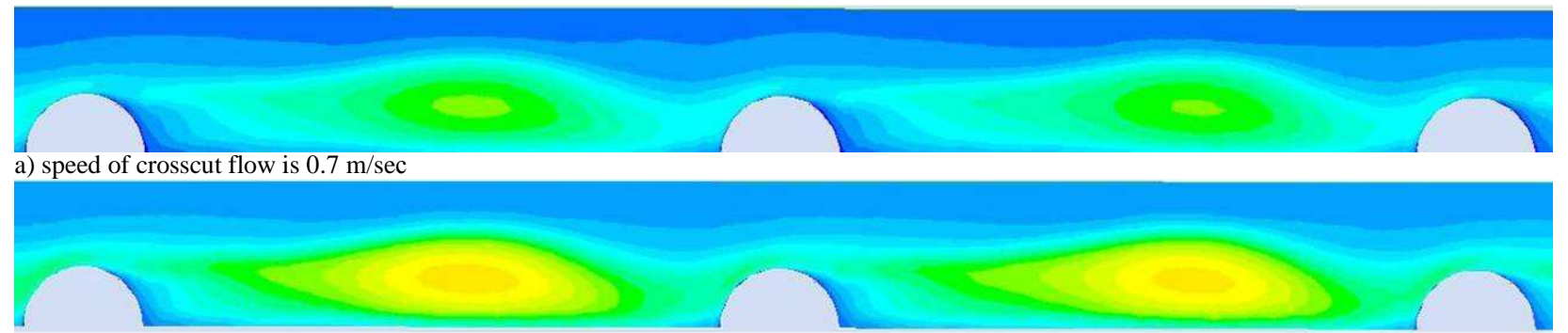

b) speed of crosscut flow is $1 \mathrm{~m} / \mathrm{sec}$

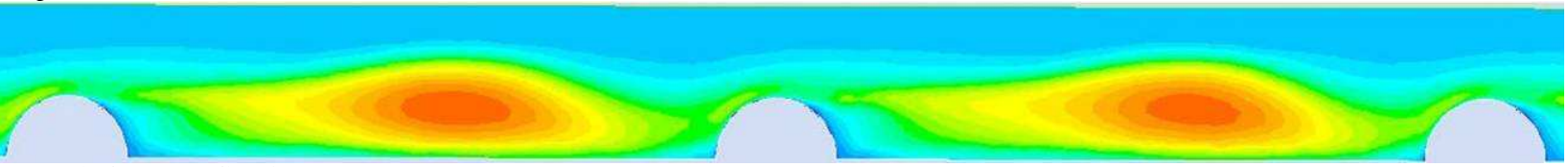

c) speed of crosscut flow is $1.3 \mathrm{~m} / \mathrm{sec}$

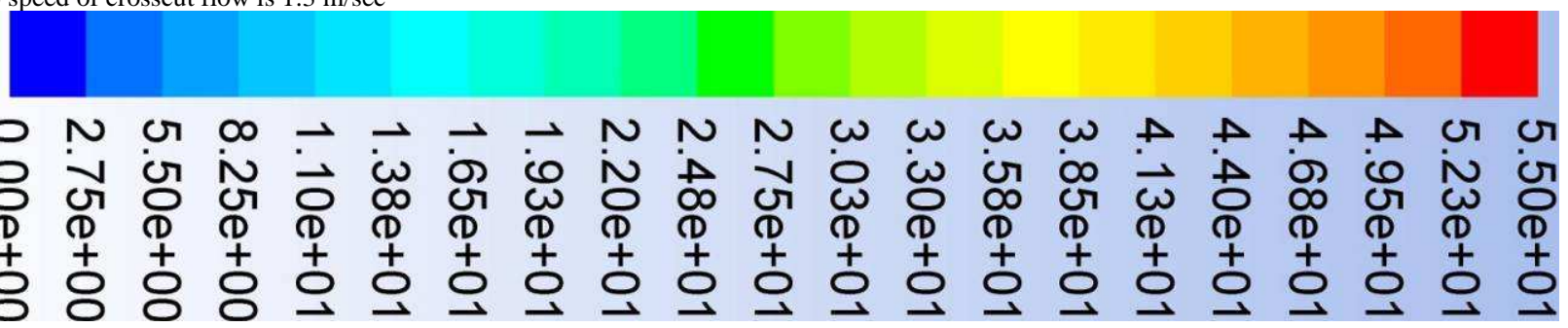

Fig. 6. Graphical allocation of the flow turbulence with different crosscut flow speeds for cylinder-formed ribs, with $6 \mathrm{~mm}$ height.

Herewith, the main task will be solved, i.e. heating a huge amount of a heat carrying agent using the same sized shell and tube heat exchangers. With the aim to test the efficacy in work of a shell and tube heat exchanger, a half way unit was developed "Autonomous heating system for high-rise apartment building".

The main goal of the experiment is to test the operability of the original shell and tube heat exchanger (patent RF 149737) in conformity with requirements SR 41101-95 (set of regulations) «Design of heating units». The exchanger temperature modes will be accepted in line with the outside temperatures for Belgorod region, defined by SR 131.13330.2012 Building Climatology. An updated edition of Construction Norms and Rules CNR 23-01-99* (with amendments No. 2).

The modes were also accepted according to the heating schedule for thermal energy delivery from a heating plant: Maisky of Belgorod District in Belgorod region (water heating unit: 3 units «Antroros» and 2 units «AB-4»; heating curve: $95-70{ }^{\circ} \mathrm{C}$ with outside temperature $-23^{\circ} \mathrm{C}$ ). 
Consequently, in order to intensify heating exchange in the shell and tube exchangers, it is reasonable to modify the heat exchange surface geometry. This entails the turbulence of the heated liquid flow and finally results in the increase of the main heat exchange parameter - the heat transfer coefficient.

\section{Acknowledgment}

The study is conducted in the framework of the Program of flagship university development on the base of Belgorod State Technological University named after V.G. Shoukhov, using equipment of the High Technology Center at BSTU named after V.G. Shoukhov.

\section{References}

[1] Set of Rules 131.13330.2012 Building Climotology. Updated edition of Construction Norms and Rules 23-01-99. RF

[2] www.minenergo.gov.ru

[3] A.Ch. Kokov, Sh.H. Aliyev, M.M. Abitov, "Modern Tendencies in Formation and Interaction of Economic Agents Within Heating and Power Systems," Economic issues, No. 10, page 79-82, 2014.

[4] Rules on Technical Operation in Thermal-Energy Plants, approved by the Order No.115 dated on March, 2003 г., RF.

[5] Shell and Tube Hheat Exchangers: catalogue of LLC Kurganchimmash, 2016, p. 82.

[6] L.S. Sterman, S.A. Tevlin, A.T. Sharkov, Thermal and Nuclear Power, M.: Energoizdat, 1982, p. 456.

[7] E. Sokolov, Industrial Heating and Heating Network. Moscow. Energoizdat, 1982, p. 360.

[8] Code of Rules 41-101-95. Design of Heating Units, Moscow, 1995, p. 79.

[9] S. Kutateladzah, Basics of Heating Exchange Theory. Moscow. Atomizdat, 1973, p. 416.

[10] A. Zhukauskas, Convection Transpot in Heating Exchangers, 1982, p. 472.

[11] J.O. Hinze, An Introduction to its Mechanism and Theory, London.:McGraw-Hill book company, 1959, p. 680.

[12] A. Alhasova, Study and Hydrodynamic Calculations Towards Inside Wells Heating Exchangers Equipped with Linear Ribs, Dissertation Research. Mahachkala, 2009, p. 143.

[13] V. Kireev, Scientific Basics and Practical Results on Efficacy Increase of Heat Exchangers. Doctoral Research, Angarsk, 2006, p. 337.
[14] A. Anisin, Energy Efficacy Increase of Smooth Pipes Beams and Profiled Channels Used for Gas-Liquid Heat Exchanging in Power Plants. Saint-Petersburg, 2009, p. 380.

[15] K.A. Olesevich, A.K. Olesevich, M.I. Osipov, "Experimental Study on Thermal Hydraulic Characteristics of Shell and Tube Heat Exchangers with Fix Bridge Bar," Vestnik of Moscow State Technical University, named after N. Bauman, No. 2, page 262 - 265, 2004

[16] A.A. Malyshev, M.O. Mamchenko, V.M. Mizin, "Modern Heat Exchangers in Low-Temperature Equipment and in Recycling Factories.," Sciemtific Journal of IFMO. Section Refridgerating Units and Conditioning, No. 1, page 38-44, 2015.

[17] G.A. Kruglov, V.V. Bakunin, M.V. Andreyeva, "Theoretical Studies on Interconnections Between Turbulence Flow and Heat Transfer Coefficient," Vestnik of Krasnoyarsk State Agriculture University, No. 6, page 67-73, 2015.

[18] V.B. Kuntysh, "Thermal Efficacy of Whirling Intensification on Gas Flow with Linear and Crosscut Flowing of Round-Piped Surfaces," Energetics. Izvestia of Hiher Institutions and Energy Idustries of CIS, No. 4, page 63-74, 2015.

[19] A.V. Golovanchikov, S.B. Vorotneva, B.A. Dulkin, "Influence of Heat Transfer Surface Ribbing on Two-Piped Heat Exchanger Productivity," Izvestia of Volgograd State Technical University, No. 1 , page $80-85,2015$.

[20] Patent No.149737 The Russian Federation MPK F28D 7/100/ ShellTube Heat Exchanger / Nikulin N., Kuschev L., Suslov D. Applicant and Patent Holder - Belgorod State Technical University. No. 2014134083/06, application dated on 19.08.14, published on 20.01.15, Bulliten No.2. 4 p.

[21] M. Miheev, I. Miheeva, Basics of Heat Transmission, Moscow. Energia, 1977, p. 344.

[22] A.A. Shlanchauskas, A.A. Pyadishyus, G.P. Zigmantas, Heat Transmissin in Turbulence Boundary Layer Film at Disturbance and Their Relaxiotion, Heat-Mass Exchange-IV. Minsk, 1980, t. 1, p. 2. 450 pages.

[23] G. Shlihting, Theory of Boundary Layer, Moscow. Nauka, 1974, p. 712.

[24] F.R. Menter, "Two-Equation Eddy-Viscosity Turbulence Models for Engineering Applications," AIAA Journal, 1994, Vol.32, No.8, pp. $1598-1605$.

[25] L.A. Kushchev, N.Yu. Nikulin, A.Yu. Feoktistov, E.A. Yakovlev, "Thermal Processes Intensification in Shell-Tube Exchanger.," Nauchny Vestnik of Voronezh State Architectural University. Building Engineering and Architecture, No. 3, page 9-17, 2016.

[26] L.A. Kushchev, N.Yu. Nikulin, A.I. Alifanova, E.A. Yakovlev, I.I. Shchekin, "Modern Methods of Thermal Exchange Intensification in Shell-Tube Heat Exchangers of Housing and Utility Infrastructue.," Vestnik of Belgorod State Technical University, No. 9, page 73 - 79, 2017. 